\section{Three Uses of the Standardized Infection Ratio (SIR) in Infection Control}

TO THE EDITOR-Just as in medicine there is no perfect drug, in mathematics there is no perfect statistic. Therefore it is not surprising that the problem of risk-adjusting rates of healthcare-associated infection (HAI) continues to provide challenges. It is true that the standardized infection ratio (SIR) has certain limitations, which were well described by Drs. Delgado-Rodriguez and Llorca in a previous letter to the editor in this journal. ' However, these limitations are not serious, and the SIR is still the best statistic available for most risk-adjustment purposes in infection control.

At least 10 different methods have been proposed for standardizing rates, but the 2 methods that have stood the test of time are indirect and direct methods. ${ }^{2,3}$ The SIR parallels the standardized mortality ratio (SMR), both of which are based on the indirect standardization method. The alternative statistic, based on direct standardization, is called the standardized rate ratio (SRR). Despite certain theoretical advantages of direct standardization approaches, a recent comparison of the SMR and the SRR found the SMR to be equally useful for public health analyses of different geographic regions. ${ }^{4}$

Likewise, despite the theoretical disadvantages of indirect standardization explained by Delgado-Rodriguez and Llorca, ${ }^{1}$ I will argue that the SIR remains the most practical riskadjustment statistic available for comparisons of HAI rates. In fact, a careful examination of the 3 most common ways infection rates are compared shows that the SIR is the most practical statistic for benchmark comparisons, intrahospital comparisons over time, and interhospital comparisons. In particular, if and when state legislation is passed that mandates public reporting of HAI rates, the SIR is the best tool available for public reporting of infection rates.

With respect to benchmark comparisons, Drs. DelgadoRodriguez and Llorca ${ }^{1}$ do not argue the fact that the SIR is a valid statistic for comparing one hospital's rate with a benchmark rate, such as the US benchmark rates from the National Nosocomial Infections Surveillance System. The numerator of the SIR is simply the number of infections that occurred at one hospital during the period under consideration. Multiplying the national standard stratum-specific rates by the number of patients the hospital has in each stratum and then summing over these strata estimates the "expected" denominator. When the hospital has "small" numerators (fewer than 20 infections in any of these strata), then the SIR is the undisputed best statistic available for this comparison.

With respect to intrahospital comparisons, Drs. DelgadoRodriguez and Llorca ${ }^{1}$ point out that the SIR might be misleading when used to compare one hospital's rates with its own previous rates over time.' I was aware of this possibility in 2000 when I proposed using the SIR for control charts of HAIs, but I did not discuss it because I believed it to be of only theoretical concern. ${ }^{5}$

For practical purposes of infection control, there are at least 3 reasons to favor the SIR over any direct method of standardizing rates for intrahospital comparisons over time. (1) The SIR gives a better estimate of the true infection rate when "small" numerators or denominators are present in some or all risk strata, (2) confidence intervals for indirectly standardized rates are narrower than those for directly standardized rates-that is, the SIR has greater precision; and (3) the distribution of patients over risk strata at a given hospital rarely changes dramatically over time, apart from random fluctuations caused by "small" numbers.

For the sake of argument, however, let us assume that the distribution of patients in different risk strata could change dramatically from month to month. Table 1 shows example SIR calculations for a hospital with exactly the same number of procedures performed (200) and exactly the same overall infection rate $(6.0 \%)$ in both June and July. The distribution of procedures performed, however, changes dramatically from 80 procedures of risk level 0 in June to 80 procedures of risk level 3 in July.

Even though the number of infections is only 12 per month, the SIR does an excellent job of adjusting for the difference in risk between June and July. There is a statistical bias in the calculation, but it is of no practical significance. The SIR declines from 1.77 in June to 1.00 in July, reflecting the fact that although many more high-risk procedures were performed July, the total number of infections remained the same.

How does a direct rate adjustment procedure fare with the same data? Table 2 shows the SRR calculations for the same hypothetical hospital. Note that, in June, the SRR of 1.794 agrees very closely with the SIR. However, in July the SRR almost doubles to 3.223 , implying that the risk-adjusted rate is much worse!

The SRR is statistically "unbiased," but as this example clearly demonstrates, the direct rate adjustment method is highly susceptible to random variation caused by small numbers. In this particular example, there are 3 infections among the 20 procedures performed in July at National Healthcare Safety Network risk level 0, for an infection rate of $15 \%$ in this stratum. Every epidemiologist knows that a rate of 3 of 20 is "unstable," and the SIR treats it as such. Unfortunately, the SRR treats this $15 \%$ rate as the "standard rate"-so the SRR itself becomes "unstable" and misleading.

The SIR remains the preferred method for risk-adjusting infection rates for intrahospital comparisons over time because the majority of monthly denominators are small (less than 1000), and therefore monthly rates are statistically "unstable." The month-to-month variation in the distribution of 
TABLE 1. Standardized Infection Ratio (SIR) Calculations for Comparison of Infection Rates During 2 Periods at a Single Hospital

\begin{tabular}{|c|c|c|c|c|c|}
\hline $\begin{array}{l}\text { Month and SIR value, } \\
\text { NHSN Risk Index }\end{array}$ & $\begin{array}{c}\text { NHSN } \\
\text { Standard } \\
\text { Infection } \\
\text { Rate, \% }\end{array}$ & $\begin{array}{c}\text { No. of } \\
\text { Procedures } \\
\text { Performed }\end{array}$ & $\begin{array}{c}\text { No. of } \\
\text { Infections } \\
\text { Observed }\end{array}$ & $\begin{array}{c}\text { Observed } \\
\text { Infection } \\
\text { Rate, } \%\end{array}$ & $\begin{array}{c}\text { No. of } \\
\text { Infections } \\
\text { Expected }^{a}\end{array}$ \\
\hline \multicolumn{6}{|l|}{ June: $\operatorname{SIR}=1.774^{\mathrm{b}}$} \\
\hline 0 & 1.40 & 80 & 3 & 3.75 & 1.120 \\
\hline 1 & 2.95 & 60 & 3 & 5.00 & 1.770 \\
\hline 2 & 4.94 & 40 & 3 & 7.50 & 1.976 \\
\hline 3 & 9.50 & 20 & 3 & 15.0 & 1.900 \\
\hline Total & $\ldots$ & 200 & 12 & 6.0 & 6.766 \\
\hline \multicolumn{6}{|l|}{ July: SIR $=1.00^{\mathrm{b}}$} \\
\hline 0 & 1.40 & 20 & 3 & 15.0 & 0.280 \\
\hline 1 & 2.95 & 40 & 3 & 7.50 & 1.180 \\
\hline 2 & 4.94 & 60 & 3 & 5.00 & 2.964 \\
\hline 3 & 9.50 & 80 & 3 & 3.75 & 7.600 \\
\hline Total & $\ldots$ & 200 & 12 & 6.0 & 12.024 \\
\hline
\end{tabular}

NOTE. NHSN $=$ National Healthcare Safety Network.

a Calculated as the NHSN standard infection rate (in \%) times the number of procedures performed.

${ }^{b}$ Calculated as the number of infections observed during the month divided by the total number of infections expected for the month.

patients in different risk strata is not the result of changes in the underlying population served, but is the result of random sampling error caused by the small numbers of operations performed each month. The SIR has an additional advantage in that the confidence intervals for indirectly standardized rates are narrower than those for directly standardized rates; that is, it has greater precision.

In 2000 I suggested plotting the monthly SIR on an individuals and moving range $(\mathrm{XmR})$ chart or a moving average and moving range $(\mathrm{mXmR})$ control chart to monitor a hos- pital's risk-adjusted infection rates. ${ }^{5}$ This method uses 2 different statistical methods designed to control for variation in infection rates. Some random variation is controlled for in the SIR itself by aggregation of rates over multiple risk strata, and the remaining random variation is used to calculate control limits. Until a better statistical method is discovered, control charts based on the SIR remain the best available statistical tool for intrahospital comparisons of HAI rates over time.

In my article published in 2000, I did not discuss the use of the SIR for interhospital comparisons both because control

TABLE 2. Standardized Rate Ratio (SRR) Calculations for Comparison of Infection Rates During 2 Periods at a Single Hospital

\begin{tabular}{lrccrr}
\hline $\begin{array}{l}\text { Month and SRR value, } \\
\text { NHSN Risk Index }\end{array}$ & $\begin{array}{c}\text { NHSN } \\
\text { No. of } \\
\text { Infections }\end{array}$ & $\begin{array}{c}\text { NHSN No. of } \\
\text { Procedures } \\
\text { Performed }\end{array}$ & $\begin{array}{c}\text { No. of } \\
\text { Infections } \\
\text { Observed }\end{array}$ & $\begin{array}{c}\text { Observed } \\
\text { Infection } \\
\text { Rate (\%) }\end{array}$ & $\begin{array}{r}\text { No. of } \\
\text { Infections } \\
\text { Expected }^{\text {a }}\end{array}$ \\
\hline June: SRR = $1.794^{\mathrm{b}}$ & & & & & \\
$\quad 0$ & 3,089 & 220,714 & 3 & 3.75 & 8,277 \\
1 & 11,219 & 380,338 & 3 & 5.00 & 19,017 \\
2 & 4,076 & 82,530 & 3 & 7.50 & 6,190 \\
3 & 2,304 & 24,263 & 3 & 15.0 & 3,639 \\
$\quad$ Total & 20,688 & $\ldots$ & 12 & 6.0 & 37,123 \\
July: SRR $=3.223^{\mathrm{b}}$ & & & & & \\
0 & 3,089 & 220,714 & 3 & 15.0 & 33,107 \\
1 & 11,219 & 380,338 & 3 & 7.50 & 28,525 \\
2 & 4,076 & 82,530 & 3 & 5.00 & 4,127 \\
3 & 2,304 & 24,263 & 3 & 3.75 & 910 \\
$\quad$ Total & 20,688 & $\ldots$ & 12 & 6.0 & 66,669 \\
\hline
\end{tabular}

NOTE. NHSN = National Healthcare Safety Network.

"Calculated as the NHSN number of procedures performed times the observed infection rate (in \%).

${ }^{b}$ Calculated as the total number of infections expected for the month divided by the total number of NHSN infections for this procedure. 
TABLE 3. Standardized Infection Ratio (SIR) Calculations for Comparison of Infection Rates During a Given Month at 2 Hospitals With Different Distributions of Risk

\begin{tabular}{|c|c|c|c|c|c|c|}
\hline $\begin{array}{l}\text { Hospital and SIR value, } \\
\text { NHSN Risk Index }\end{array}$ & $\begin{array}{c}\text { NHSN } \\
\text { Standard } \\
\text { Infection } \\
\text { Rate, \% }\end{array}$ & $\begin{array}{c}\text { Actual No. of } \\
\text { Procedures } \\
\text { Performed } \\
\end{array}$ & $\begin{array}{c}\text { Adjusted No. of } \\
\text { Procedures } \\
\text { Performed }^{\mathrm{a}}\end{array}$ & $\begin{array}{c}\text { No. of } \\
\text { Infections } \\
\text { Observed }\end{array}$ & $\begin{array}{l}\text { Observed } \\
\text { Infection } \\
\text { Rate, } \% \\
\end{array}$ & $\begin{array}{c}\text { No. of } \\
\text { Infections } \\
\text { Expected }^{\mathrm{b}}\end{array}$ \\
\hline \multicolumn{7}{|l|}{ Hospital A: SIR $=1.886^{\mathrm{c}}$} \\
\hline 0 & 1.40 & 72 & 80 & 2 & 2.50 & 1.120 \\
\hline 1 & 2.95 & 37 & 50 & 3 & 6.00 & 1.475 \\
\hline 2 & 4.94 & 52 & 40 & 4 & 10.00 & 1.976 \\
\hline 3 & 9.50 & 39 & 30 & 5 & 16.66 & 2.850 \\
\hline Total & $\cdots$ & 200 & 200 & 14 & 7.00 & 7.421 \\
\hline \multicolumn{7}{|l|}{ Hospital B: SIR $=1.886^{\mathrm{b}}$} \\
\hline 0 & 1.40 & 48 & 40 & 3 & 7.50 & 0.560 \\
\hline 1 & 2.95 & 38 & 25 & 2 & 8.00 & 0.738 \\
\hline 2 & 4.94 & 8 & 20 & 1 & 5.00 & 0.988 \\
\hline 3 & 9.50 & 6 & 15 & 1 & 6.66 & 1.425 \\
\hline Total & $\ldots$ & 100 & 100 & 7 & 7.00 & 3.711 \\
\hline
\end{tabular}

NOTE. NHSN = National Healthcare Safety Network.

a Calculated by combining the 200 procedures at hospital $\mathrm{A}$ and the 100 procedures at hospital $\mathrm{B}$, then allocating them so that the distribution across risk strata at each hospital matches the distribution of the combined data.

b Calculated as the NHSN standard infection rate (in \%) times the number of procedures performed for the 2 hospitals combined.

' Calculated as the number of infections observed at the hospital divided by the total number of infection expected for the month.

charts are not designed this purpose and because there appeared to be little likelihood that interhospital comparisons of HAI rates would ever be required. ${ }^{5}$ Recently, however, the majority of US states have either passed or are considering legislation mandating the reporting of HAI rates to the public. As regulations implementing these public reporting statutes are drafted, state health officials and hospital infection control professionals will be challenged to find methods that provide meaningful interhospital comparisons that are easily interpreted by consumers and purchasers.

Most of the reasons for preferring the SIR for intrahospital comparisons also apply to interhospital comparisons. The SIR still performs better than the SRR when "small" numerators or denominators occur in some or all risk strata, and the SIR still has greater precision than the SRR. Since most US hospitals perform small numbers of operations (fewer than 100 per month), the "unstable rates" problem discussed above would make the SRR extremely unreliable. Furthermore, for publicly reported rates, some consideration must be given to how easily the risk-adjustment method can be explained to consumers. The SIR is by far the easiest risk-adjustment statistic to explain-it is simply the number of observed infections divided by the number of expected infections after "leveling the playing field."

In the case of interhospital comparisons, however, it is clear that the distribution of patient risk differs widely between hospitals. For example, cancer hospitals, children's hospitals, trauma center hospitals, suburban hospitals, and rural hospitals serve distinctly different patient populations with different distributions of intrinsic patient risk. Furthermore, even the theoretical possibility of bias in the published rates could undermine the public's trust in such comparisons. Accordingly, for interhospital comparison purposes, the statistical bias in the SIR discussed by Drs. Delgado-Rodriguez and Llorca ${ }^{1}$ deserves special attention.

Fortunately, there is a way to keep all the benefits of the SIR for interhospital comparisons and to minimize the bias resulting from the differing distribution of patient risk. The statistical bias in indirect rate standardization is introduced when the distribution of procedures across risk strata is different for the 2 hospitals being compared. It disappears if the combined distribution of procedures is used to calculate the SIR for each hospital. ${ }^{6}$ To accomplish this, we adjust the number of the procedures done at each hospital to match the combined distribution for both hospitals across the various risk strata. These computations are illustrated in Table 3. Since both of these example hospitals have overall infection rates of $7.0 \%$, adjusting to the same distribution of procedures across risk strata results in both hospitals having the same SIR (1.886).

In a state with 100 hospitals, comparing every hospital with every other hospital involves 4,950 comparisons, for a total of 99 SIR calculations for each hospital. Fortunately, with a computer these calculations are trivial, and the least biased estimate of the SIR would be the median of all the SIR values calculated for a given hospital.

Despite the theoretical disadvantages of indirect standardization, in the practical world of infection control, the SIR remains the best risk-adjustment statistic available for comparisons of HAI rates. This is true for benchmark comparisons with a national database because that is the original purpose of the SIR. The SIR is also best for intrahospital 
comparisons of HAI rates over time because monthly rates are "unstable," whereas the distribution of patient risk factors is relatively stable. Finally, the SIR is also the best statistic available for interhospital comparisons of HAI rates, if one is careful to perform only pairwise comparisons of hospitals with their combined distribution of patients across risk strata. Given that the SIR is also the easiest risk-adjustment method to explain to consumers, I believe the SIR will provide the best tool available for public reporting of risk-adjusted infection rates.

\section{Tracy L. Gustafson, MD}

\section{REFERENCES}

1. Delgado-Rodriguez M, Llorca J. Caution should be exercised when using the standardized infection ratio. Infect Control Hosp Epidemiol 2005; 26: 8-9.

2. Inskip $H$, Beral V, Fraser P, Haskey J. Methods for age adjustment of rates. Stat Med 1983; 2:455-466.

3. Julious SA, Nicholl J, George S. Why do we continue to use standardized mortality ratios for small are comparisons? J Public Health Med 2001; 23: 40-46.

4. Goldman DA, Brender JD. Are standardized mortality ratios valid for public health data analysis? Stat Med 2000; 19:1081-1088.

5. Gustafson TL. Practical risk-adjusted quality control charts for infection control. Am J Infect Control 2000; 28:406-414.

6. Rothman KJ. Modern Epidemiology. Boston: Little-Brown Boston; 1986: 41-49.

Dr. Gustafson is from Infection Control and Prevention Analysts, Austin, Texas.

Address reprint requests to Tracy L. Gustafson, MD, Infection Control and Prevention Analysts, Inc., 515 S. Capital of Texas Highway, Suite 240, Austin, TX 78746 (tlgustafson@sbcglobal.net).

Infect Control Hosp Epidemiol 2006; 27:427-430

(C) 2006 by The Society for Healthcare Epidemiology of America. All rights reserved. 0899-823X/2006/2704-0020\$15.00. 